\title{
ENVIRONMENTAL EFFECTS OF AIRPORT NODES: A METHODOLOGICAL APPROACH
}

\author{
M.N. POSTORINO \\ Department of Computer Science, Mathematics, Electronics and Transports, \\ Mediterranean University of Reggio Calabria, Italy.
}

\begin{abstract}
Airports are a local source of environmental impacts that should be estimated and evaluated in order to promote the right development of these transport nodes. The aim of this paper is to present a methodological approach to identify the environmental impacts produced by an airport node, particularly atmospheric pollution produced not only by aircraft but also by land vehicles for handling operations and airport connections, given the airport multifunction role as well as its interchange multimodal function. The identified methodology is formed by several steps; the most relevant ones address the estimation of the air transport demand (linked to the number of aircraft movements) and the car mode share to go in and out of the airport. The proposed methodology is useful in order to establish standard procedures to identify the airport environmental impact footprint for a sustainable development of the air transport within the larger transport system.
\end{abstract}

Keywords: air transport demand module, airport catchment area module, airport nodes, carbon footprint, environmental impact assessment, ground movement module, transport function.

\section{INTRODUCTION}

Transport systems generally represent one of the most important pollution sources, mainly in terms of noise, atmospheric pollution and land consumption. Furthermore, often they depend on non-renewable energy resources. With particular reference to the air transport system, an airport produces many environmental impacts that not only reduce the wellness degree of the communities living close to the airport area, but also represent a limit to the growth of the air traffic if any effective measure is taken to reduce them $[1,2]$.

On the one hand, the local communities obtain the main benefits from their nearby airport and its growth, on the other hand, they suffer from environmental negative impacts produced by it. For this reason, both at international (ICAO) and local (e.g. UE, European Aviation Safety Agency - EASA, Federal Aviation Administration - FAA, and so on) levels, the main government associations fix goals, priorities and duties of the several actors involved in the air transport system in order to guarantee the sustainable development of the air transport industry at global level and the well-being of local communities as well.

Generally, an airport is a local source of impacts that can be grouped into two macro-classes: impacts produced by the infrastructure and impacts produced by the transport function (Fig. 1).

The first one depends on the airport's overall characteristics and includes: visual impacts, groundwater impacts and produced waste, among the many others that can be identified starting from an Environmental Impact Assessment (EIA) analysis [3]. The second one is linked to the transport features and their effects, the most important being noise and atmospheric pollution, particularly at local level $[4,5]$.

Actually, noise during the landing/take-off operations or along the aircraft approach path is one of the most discussed impacts on the population living in the airport area. Generally, people are more sensitive to noise impacts as they produce immediate effects, e.g. the interruption of the current activities due to the aircraft passage, the disturbance of silence needed to carry out some work activities or to guarantee suitable conditions (for example, schools, hospitals, residence areas and so on); finally, they also depend on the individual response to the environmental problems.

(C) 2010 WIT Press, www.witpress.com

ISSN: 1743-7601 (paper format), ISSN: 1743-761X (online), http://journals.witpress.com

DOI: $10.2495 / \mathrm{SDP}-\mathrm{V} 5-\mathrm{N} 2-192-204$ 


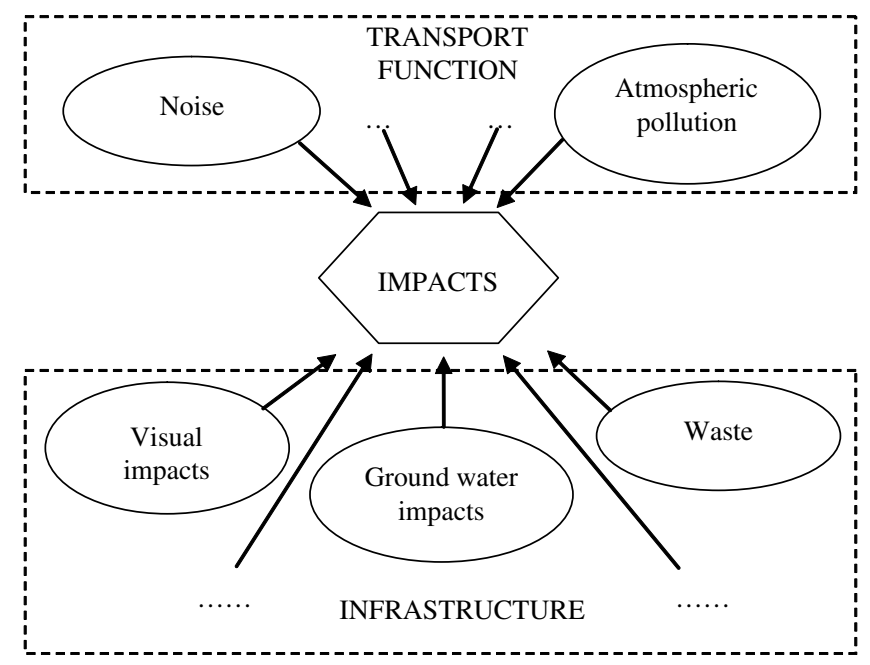

Figure 1: Impacts produced by an airport node.

For this reason, more attention has been devoted to the reduction of noise, particularly in terms of aircraft technological improvements (e.g. Aircraft Noise Certification as fixed by the Annex 16, ICAO [6]) and/or constraints at airports (e.g. reduction of the movements during some day periods, following the EU Directive 2002/49/EC [7]).

Atmospheric impacts are generally considered less relevant due to several improvements, in terms of fuel burn, that offer more efficient and less pollutant aircraft. The most important aircraft emissions are carbon dioxide $\left(\mathrm{CO}_{2}\right)$, water vapor $\left(\mathrm{H}_{2} \mathrm{O}\right)$ in terms of condensation trails and nitrogen oxides $\left(\mathrm{NO}_{\mathrm{x}}\right)$. Anyway, as estimated by the Air Transport Action Group [8] new aircrafts are $70 \%$ more fuelefficient than they were 40 years ago, carbon monoxide emissions have been reduced by $50 \%$, unburned hydrocarbon and smoke have been cut by $90 \%$. Many research programs are currently in progress in order to realize at least $50 \%$ fuel and $\mathrm{CO}_{2}$ savings, as well as $80 \%$ reduction in $\mathrm{NO}_{\mathrm{x}}$, by 2020. In the light of a more environmental friendly development, research efforts have been made to test alternative fuels for aviation, particularly new generation of sustainable biofuels. The use of biofuels in commercial flights can meet the requirements of the Kyoto Protocol and then contribute to the sustainable transport development, but it requires an effort by all the involved actors to accelerate the commercialization and implementation of aviation biofuels. Aircraft emissions can be estimated at cruising altitudes and at ground (or local) level, during landing/take-off operations and taxiing. For the latter, the percentage of aircraft-related emissions is generally small as regards the total amount generated by ground airport activities and land traffic around airports. Although the several aspects (e.g. social, environmental, monetary) of aircraft impacts at airports have been studied in the literature (as in [9-12]), to the best of my knowledge there are no researches trying to establish a comprehensive approach to identify the 'airport carbon footprint' due not only to aircraft-related operations but also to land airport activities (e.g. handling) and surface connecting transport modes.

In the light of the sustainable mobility development and to reduce the greenhouse emissions, it is desirable that the overall impacts produced by an airport node, particularly $\mathrm{CO}_{2}$ emissions, are estimated and above all suitably managed in order to be less than prescriptive environmental constraints. Then, the goal of this paper is to define a methodological approach to identify the impacts produced by the airport transport function (particularly atmospheric pollution produced by aircraft and land vehicles going in and out of the airport as well as land vehicles for handling operations) in order to 
ascertain the contribution of each pollutant sources to the airport carbon footprint. The paper is structured as following: the proposed methodology is described in Section 2, while the next sections ( 3 and 4) depict the several modules in detail. Section 5 summarizes the impact contributions together with a simplified application to a test case. Finally, the main conclusions are reported in Section 6 .

\section{A GENERAL OVERVIEW OF THE PROPOSED APPROACH}

The airport carbon footprint depends not only on the transport function, but also on other airport-related activities (e.g. conditioning sources for airport workplaces). Anyway, in this paper only the emissions linked to the transport function will be considered in the following, due to their social relevance.

Figure 2 summarizes the several modules of the methodology, consisting of some main steps. The first step is aimed at identifying the airport (origin and/or destination) catchment area, in order to determine the potential air demand at the airport itself and the percentage of users choosing among the different ground transport modes to go in and out of the airport. The airport catchment area depends on many factors such as airport geographical position, land connecting transport system, socio-economic characteristics of potential users and existence of competing airports. This step is strongly linked to the following one, concerning the air transport demand estimate; in turn, this stage is linked to the estimate of the number of movements at a given airport, and then the related environmental ground effects that depends on the expected air transport demand. Both passengers and goods should be considered, but goods volumes are almost negligible with respect to passenger volumes.

Air demand estimate and airport catchment area are strongly related, as, depending on the approach, the catchment area identifies the potential demand for the airport. The demand on the several ground transport modes to go in and out of the airport, in turn, depends on the overall air transport demand. In fact, air travelers use one of the available land modes (e.g. car, train, buses and others) to go in and out of the airport; demand on each mode depends on the overall air demand level and the estimated ground mode share.

The third step deals with the estimate of the aircraft (or movements) number to support the computed air transport demand in order to estimate the impacts produced by aircraft at ground level; this number depends on the aircraft average load factor. Furthermore, depending on the number of movements, the number of land vehicles operating within the airside can also be computed as well as their impacts.

Then, for each step, impacts due to surface connecting modes, land vehicles operating within the airside and aircraft can be estimated, thus giving the 'airport carbon footprint' due to transport activities; the estimated overall impact can be compared with the prescriptive environmental constraints.

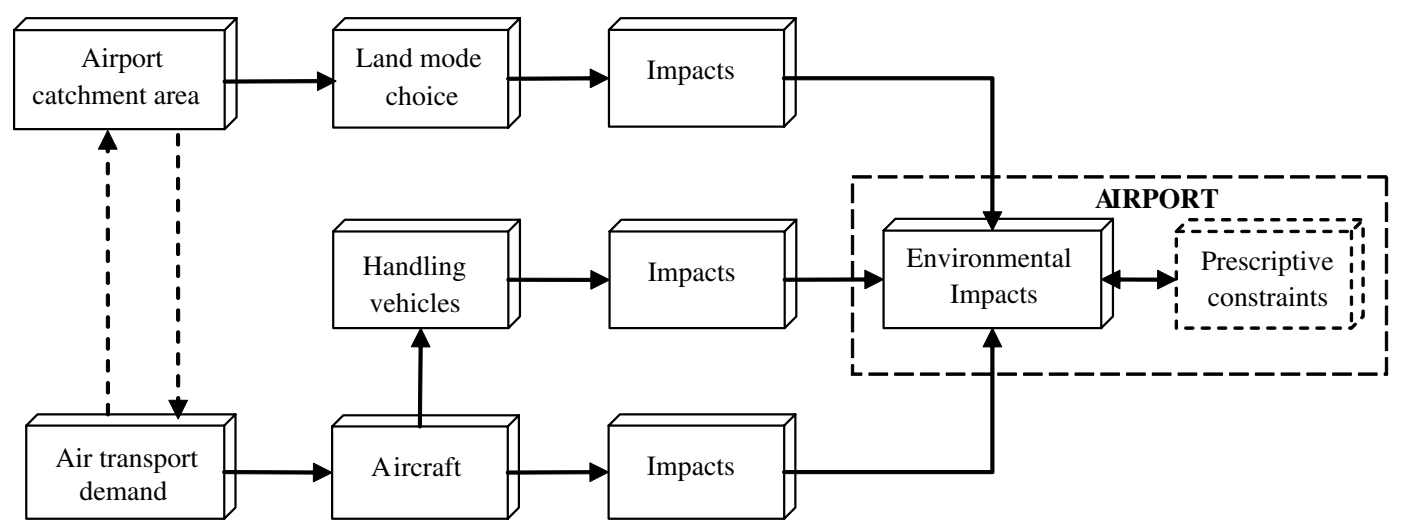

Figure 2: The general procedure to identify the airport carbon footprint due to transport activities. 
The procedure is particularly useful to test the developing capabilities of airports, mainly regional airports giving the role they are called to play (e.g. alternative nodes with respect to congested main airports, economical engine of decentralized regions, and so on). In fact, the estimate of the different contribution to the carbon footprint can be used to identify the best managing strategies when the pollutant values are greater than the prescriptive environmental constraints, thus promoting an environmental friendly development of the airport satisfying the concept of transport sustainability. As an example, airport developing strategies can be verified a priori in terms of carbon footprint produced by each component. If the car share prediction to go in and out of the airport is significant, and then the environmental effects are significant as well, a suitable policy is to improve airport connections to public transport networks (e.g. rail or buses) to reduce car share by encouraging users to choose public transport systems. This can be particularly useful in EU, where many projects promoting the accessibility of some regions (and transport terminals as well) are in progress and some others are encouraged by the European Commission to develop the Trans European Network-Transport, TEN-T [13]. Then, airports can be inserted as nodes in the public transport European network and linked to the surrounding areas, thus improving their accessibility. For example, larger airports (like Paris Charles de Gaulle or Frankfurt) already have direct links with high-speed rail services, but developing regional airports could plan their connections as well, not only to better link the airport to the surrounding areas but also to promote a sustainable development by reducing the airport carbon footprint.

The following sections will describe in detail the several modules of the proposed procedure.

\section{THE AIRPORT CATCHMENT AREA AND AIR DEMAND MODULES}

The airport catchment area can be defined with reference to land extension or user demand. In terms of land extension (or geographic point of view) it represents the area generating (attracting) users at an airport; in other words, it can be defined as the area where potential air travelers for a given airport start or end their overall air trip. In terms of user demand, the airport catchment area can be defined as the number of air travelers using a given airport.

Actually, both points of view give final results as the number of users at a given airport starting/ ending their air trip in an airport surrounding area. The main difference is that the first definition involves the identification of an area where air travelers are contained, while the second one involves the computation of airport choice probabilities for each identified Transportation Analysis Zones (TAZ), defined as 'a geographic area that identifies land uses and associated trips that is used for making land use projections and performing traffic modeling' [14].

Figure 3 describes the main elements of the airport catchment area module. The identification of the catchment area in geographical terms, generally corresponds to the definition of some accessibility measures to identify a territory extension, within a prefixed travel time (or distance), where it is reasonable to locate origins and/or destinations of airport users. Computation of accessibility measures often requires the use of surface transport networks in order to estimate an impedance function that represents the separation between pairs of activity centers in a given area (see, for example, [15]). In order of complexity, accessibility measures can be distinguished in isochronic, gravity-based and utility-based measures, defined respectively as

$$
A_{i}=\sum_{j=1, \ldots, J} B_{j} a_{j} \quad A_{i m}=\sum_{j} a_{j} g\left(C_{i j m}\right) \quad A_{i}^{n}=\ln \left[\sum_{j=1, \ldots, J(n)} \exp \left(V_{j(n)}\right)\right]
$$

where $A_{i}, A_{i m}$ and $A_{i n}$ are accessibility in $i$, respectively, to the potential destinations $j$, to the potential destinations $j$ by mode $m$ and for user $n ; a_{j}$ is the number of activities in $j$ or attractiveness of destination $j$; $B_{j}$ is Boolean variable: 1 if $j$ is within a given travel distance (or time), 0 otherwise; $C_{i j m}$ is 


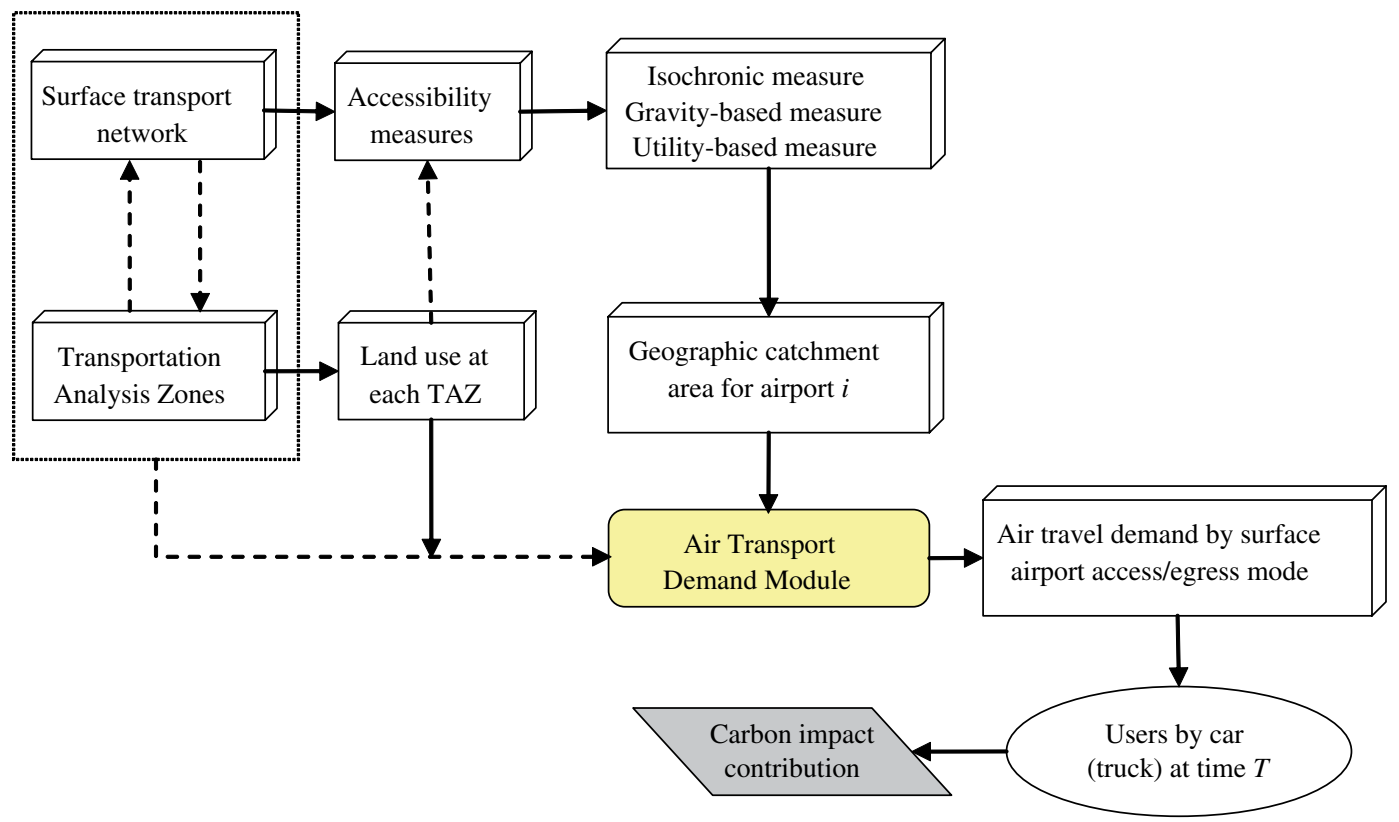

Figure 3: Airport catchment area module.

generalized travel cost between $i$ and $j$ by mode $m ; g\left(C_{i j m}\right)$ is the impedance function between $i$ and $j$ by mode $m$, e.g. of the form:

$$
g\left(C_{i j m}\right)=C_{i j m}^{-2} \quad g\left(C_{i j m}\right)=\exp \left(\theta \cdot C_{i j m}\right), \theta<0
$$

and $V_{j}(n)$ is utility of destination $j, J(n)$ being the set of alternatives $j$ available to user $n$.

Specifically, the first two measures can be used to identify a geographical catchment area for an airport. Note that both origin and destination catchment areas can be identified, as they are generally different (e.g. available surface modes to connect the airport are different and so are the catchment areas at origin and destination airports).

The estimate of the generalized travel cost (usually a combination of time, monetary costs and some other quantities representing the travel disutility) requires the use of regional transportation planning models, based on TAZ land partition and transport network representation that, in turn, are also necessary to employ a trip demand model.

Population living in the airport catchment area are potential users of that airport and then the percentage of them using car to go in and out of the airport can be estimated by using stage demand models, as in the 'air transport demand' module (Fig. 4), the inputs being the network representation and the TAZ land partition. The goal of the air transport demand module, in this case, is not simply the estimate of the air demand at an airport at time $T$, but particularly the estimate of the air traveler percentage using the several available surface airport connecting modes. As described in Fig. 4, both time series and stage models can be used to obtain this result, particularly stage models need to estimate the percentage of users that go in and out of the airport by surface transport modes.

As known, time series models $[16,17]$ try to explain the trend of an event (such as the passenger volumes at an airport during a time period) on the basis of its realized past values and they have been 


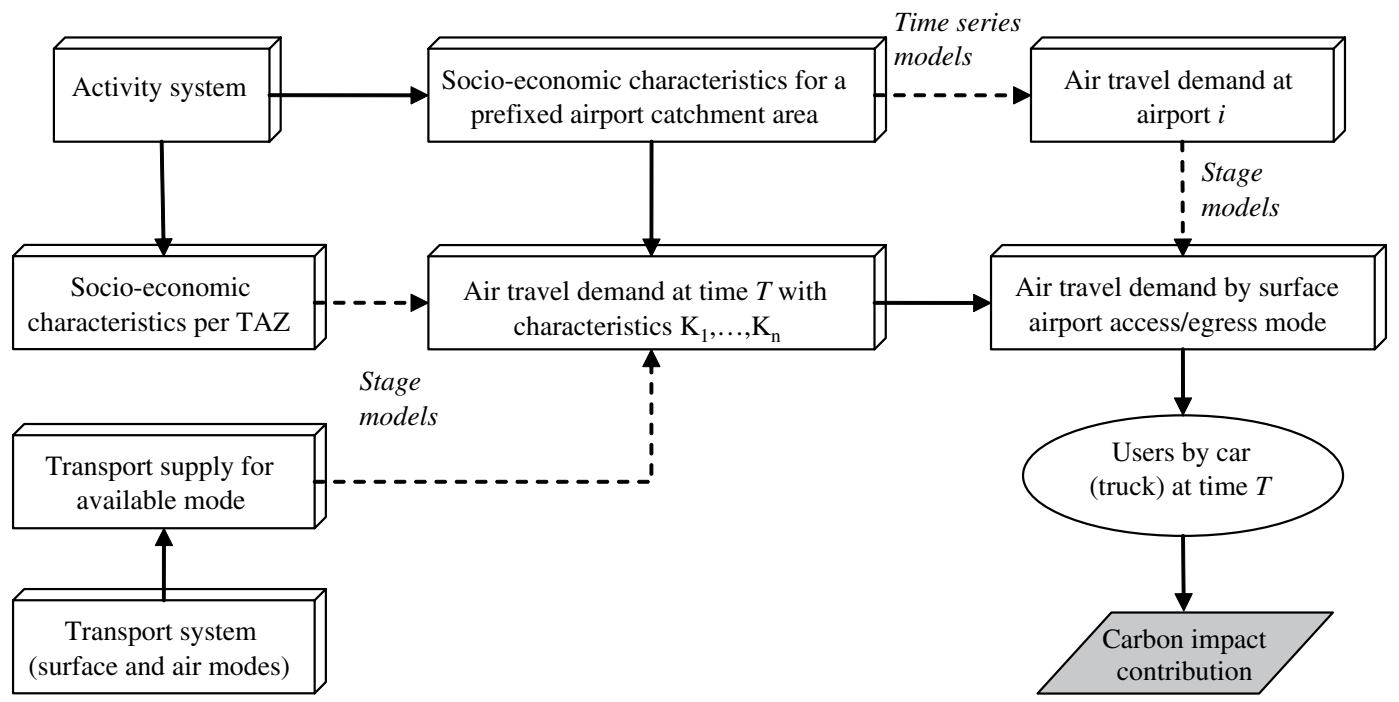

Figure 4: Air transport demand module.

widely used to obtain air demand estimates at an airport (see, among the others, [18-22]). Simplest models are of the following form:

$$
\begin{gathered}
d_{i t}=\beta_{0}+\boldsymbol{\beta}^{T} \boldsymbol{y}_{i t}+u_{i t} \\
u_{i t}=\rho u_{i, t-1}+\varepsilon_{i t}
\end{gathered}
$$

where demand at an airport $i$ at time $t, d_{i t}$, is a function of $n$ explanatory variables $\boldsymbol{y}_{i t} . \boldsymbol{\beta}^{T}$ are the unknown model parameters, $\beta_{0}$ the model constant, $u_{i t}$ a random term, $\varepsilon_{i t}$ a White Noise random residual and $\rho$ the autocorrelation parameter taking into account the time dependence among the variables. When a geographical catchment area has been identified for a given airport, time series models (1) and (2) can be applied at that airport; explanatory variables (e.g. population or income) refer to the identified catchment area.

Stage models, mainly used together with a discrete choice approach, are of the following form:

$$
d_{o}\left(s, k_{1}, k_{2}, \ldots, k_{n}\right)=n_{o} \prod_{c} p\left(k_{c}\right)
$$

where $d_{o}\left(K_{1}, K_{2}, \ldots, K_{n}\right)$ is the travel demand with origin in TAZ $o$, traveling for trip purpose $s$ (e.g. leisure or business) and characterized by the choice dimensions $K_{1}, K_{2}, \ldots, K_{n}$ (as trip destination, departure time, travel mode, origin and/or destination airport if the mode is aircraft, and so on); $n_{o}$ is the number of potential travelers in the origin zone $o ; p\left(K_{c}\right)$ are the choice percentages referred to the $K$ choice dimension; several random utility models as Logit, Nested-Logit, Cross-Nested Logit models and so on (see for example Train [23] for an overview), can be used to estimate $p\left(K_{c}\right)$. Suitably specified, model (3) gives the air demand at airport $i$ by explicitly defining the choice of an airport among some competitive others, thus estimating the catchment area in terms of user demand. If the choice percentage of surface mode $m$ to/from airport $i$ is also computed, air travel demand by airport surface connecting mode $m, d_{i m}$, can be estimated, particularly users by cars (or truck if users are goods).

The choice sequence in model (3) is not known a priori and then the estimate of $d_{i m}$ is not trivial as the user choice process referring to the air mode can be complex (air choices have been widely studied in the literature, see, for example, [24-30]). In fact, air travelers make many choices 
concerning, among the others, the origin and/or destination airports, their surface connecting modes, the air services at airports, and so on. Actually, several choices are strongly linked to each other and it is not easy to identify a hierarchical relationship, if any, among them; furthermore, if a hierarchy exists it is also erratic from user to user according to the context.

Following Fig. $4, d_{i m}$ is obtained as a result of a suitably specified model (3), if only stage models are used; on the contrary, it is obtained as a combination of time series and stage models if both are used to compute, respectively, the air travel demand at airport $i, d_{i}$, and then the choice percentage of surface mode $m$ given airport $i, p(m / i)$, in order to obtain $d_{i m}$ as the product between $d_{i}$ and $p(m / i)$.

\section{THE GROUND MOVEMENT MODULE}

Land vehicles and aircraft move within the airside to accomplish many activities. Land vehicles are involved in handling operations such as refueling, cleaning, catering, baggage transfer and so on (there are service vehicles to transfer staff and crew members as well), and they move among aprons following the aircraft schedule needs. Number and traveled distances of handling vehicles depend on the characteristics of the airport and its airside, thus producing pollutant emissions directly linked to these aspects as well as to their technological characteristics.

Aircraft on ground produce pollutant emissions resulting directly from aircraft flights and include emissions associated with taxiing and the use of auxiliary power units (APUs) at gates.

Figure 5 describes the elements forming the ground movement module, by considering the air user demand at the origin airport.

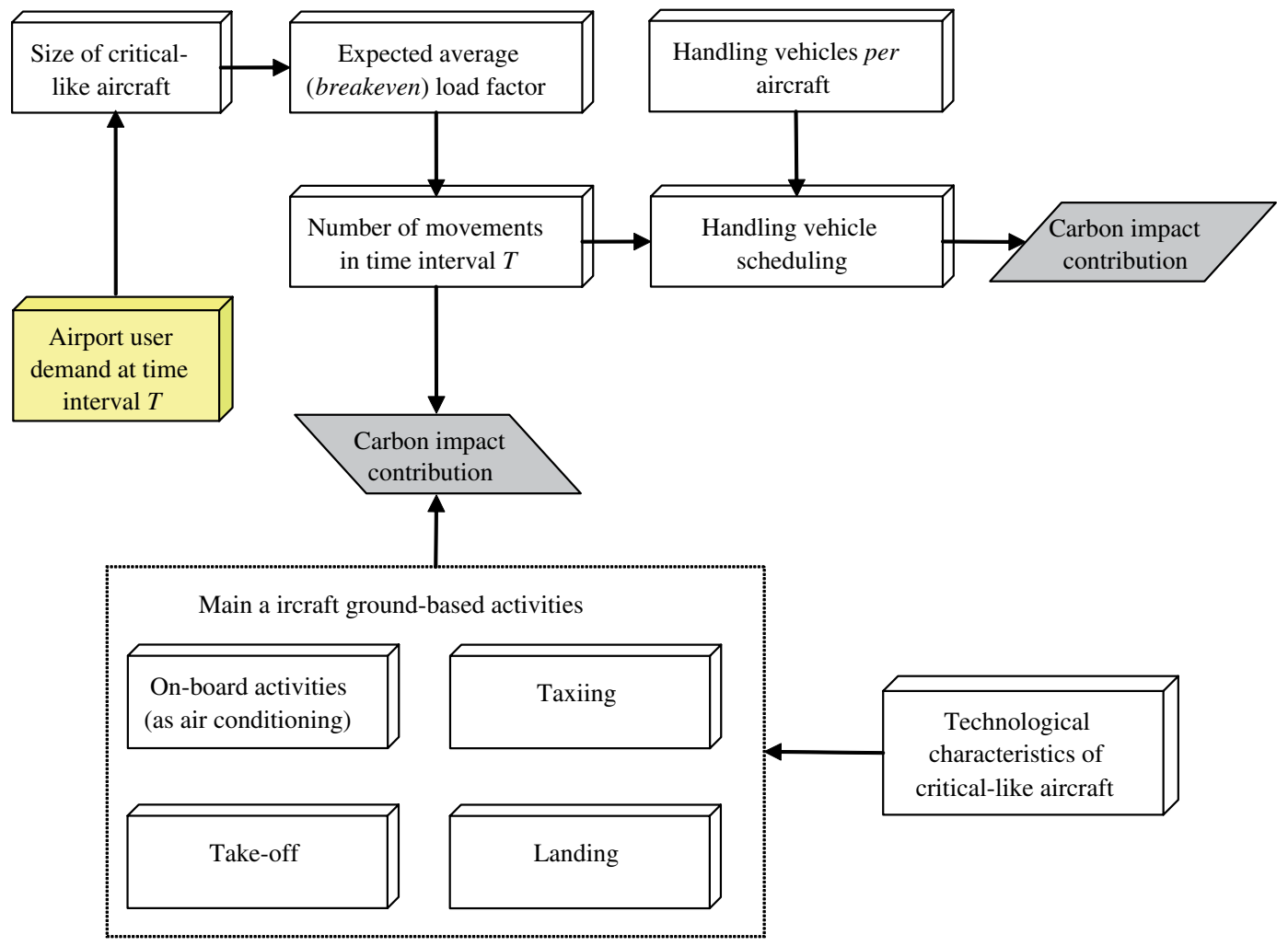

Figure 5: Ground movement module. 
As known, the characteristics of an airport are designed and evaluated according to the "critical aircraft' [31], i.e. the aircraft type that is expected to use the airport more frequently. Ground-based emissions at the airport can then be estimated in accordance with the critical aircraft.

Following Fig. 5, the air user demand at the examined airport during time $T$, can be converted into number of aircraft (or more specifically movements) by using the expected average load factor (or alternatively the expected breakeven load factor if efficiency considerations are taken into account as well) for the critical aircraft.

Handling vehicle operations depend on the number of movements, the flight scheduling, the airside size and configuration. Handling-based emissions then depend not only on the above factors, but also on the characteristics of the vehicles themselves (age, type of fuel, fuel efficiency and so on).

By contrast, the overall aircraft ground-based emissions are a function of the number of movements, according to the characteristics of the critical aircraft on average. Emissions due to landing and take-off operations refer to the first and last stages respectively, i.e. in the neighborhood of the airport. Furthermore, aircraft on ground produce additional emissions mainly due to taxiing and the use of APUs [32].

Taxiing at an airport is a function of its configuration, then the amount of taxi/idle varies significantly from airport to airport; generally, longer distances from runway(s) to aprons mean a greater fuel use and in turn greater emissions. The variance in taxi/idle time produces variability of aircraft emissions during airport operations, thus suggesting the use of models linking the aircraft technological characteristics (in terms of fuel efficiency) to the airport size and/or configuration. Furthermore, many factors can contribute to the reduction of taxiing-based aircraft emissions, as the use of high-speed taxiways, last-minute start-up, realignment of taxiways, improvements at the gate area, and taxiing in with minimal engines running.

The other significant source of emissions comes from the use of APUs. APUs are engine-driven generators, generally present in the aircraft tail, providing the aircraft with necessary energy (e.g. for air conditioning, lights, and so on) during the time it is at the gate. Then, though stationary, the aircraft continues consuming energy and then producing emissions.

To conclude this section, a brief consideration about the potential link between aircraft noise mitigation measures and their effect on fuel use. Following some studies [31] there could be situations where application of hushkits could lead to an increase in fuel consumption of up to 5\%, though lightweight hushkits may have a negligible effect on fuel use. Anyway, following the approach used in this paper, airport carbon footprint is as important as environmental noise impacts and all the aspects involving an increase in the carbon emissions should be considered.

\section{CARBON IMPACT CONTRIBUTIONS AND TEST CASE}

In environmental terms, transportation efficiency can be defined as the fuel needed to transport one person over a distance of $1 \mathrm{~km}$, i.e. the energy required per passenger-km. As regards freight, comparison between aircraft and other transport modes is more complex as there could be differences among different modes (e.g. weight restrictions). The possible restrictions being assumed, in this case transportation efficiency can be defined on the basis of energy use per tonne-km. The main goal of planners and analysts of transportation systems is the reduction of the energy required to move the user reference unit, both for financial and environmental purposes (e.g. if the required energy decreases, the environmental impacts produced are less).

Figure 6 summarizes the carbon impact sources due to aircraft and land vehicles at airports. According to the characteristics of the critical aircraft and/or the (expected) fleet composition, ground-based aircraft emissions can be estimated on the basis of the main operations performed at the airside. 


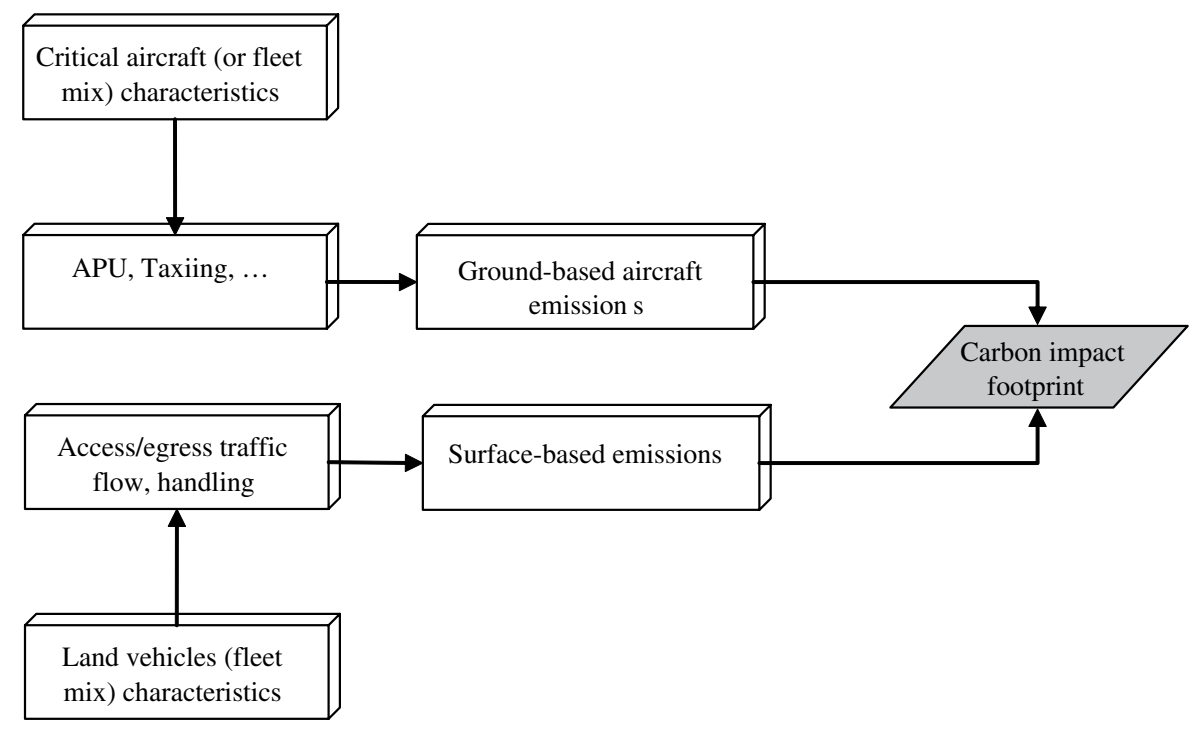

Figure 6: Carbon impact footprint due to aircraft and land vehicles.

Generally, old aircraft use much more fuel per passenger-km than new aircraft of similar size (as an example, the required energy per passenger-km is within 1.0-3.0 MJ per passenger-km), but airlines tend to optimize the use of their aircraft in order to reduce operational costs. Then, apart from environmental considerations, in any case airlines try to optimize the utilization of an aircraft as much as possible and to reduce fuel consumption. As regards APUs, fuel used by them is only a relatively small part of the overall aircraft fuel consumption (recent estimates evaluate that the amount of APU fuel ranges from $0.8 \%$ to $3.5 \%$ of the overall aircraft fuel). Anyway, energy required by APUs, can also be obtained by means of suitable ground-based electrical equipment with a significant net saving of carbon emissions.

On the other side, handling vehicles can produce significant carbon emissions, according to the airside and vehicle characteristics, as well as the percentage of users traveling by road individual transport means.

Generally, land vehicle emissions depend on both drive conditions and vehicle type. In fact, speed and acceleration, driving on flat or slope surface as well as engine conditions, the presence of elements for containing emissions and operation types are elements that strongly influence both the type and quantity of carbon emissions. Although land vehicle emissions due to handling can be quite easily estimated, operations and airside configuration being known, estimates of emissions due to road individual vehicles can be more difficult according to the point of view. If only the contribution at airports is considered, just the shares due to trips within the landside should be considered, and they can be computed as same as the emissions due to handling, by considering the (average) characteristics of individual transport means. By contrast, contributions can be referred to the overall trip to/from the airport; in this case, other than the air travel demand by airport connecting road individual mode, at least the traveled mean distances should be known in order to compute the carbon contribution at aggregated level. More in-depth analyses can be performed in terms of road traffic flow to/from the airport, by using road demand assignment models.

The proposed general procedure, at a simplified level, has been used to compute the carbon contributions at the airport of Reggio Calabria (Southern Italy, Fig. 7) on the Messina Strait that separates 


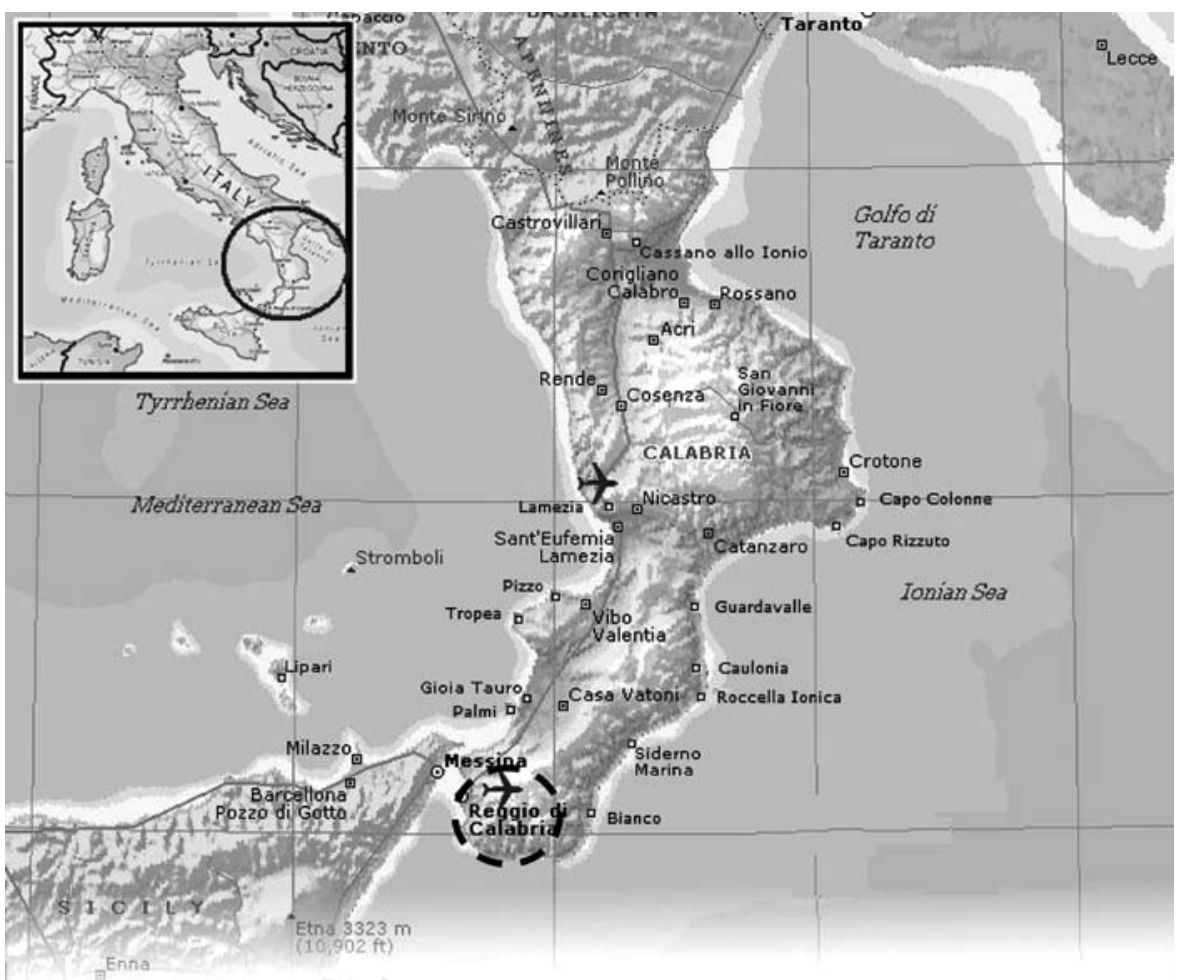

Figure 7: Reggio Calabria Airport (Southern Italy) geographical position.

the Sicily isle from continental Italy, specifically the Calabria region where Reggio Calabria airport is located. The airport geographical catchment area corresponds more or less to the administrative province of Reggio Calabria and the administrative area of the city of Messina, in the Sicily isle.

The yearly demand at the airport in the last 2 years has been less then 500,000, because of the current economic situation together with the strong competition of the near by airport of Lamezia Terme (about $140 \mathrm{~km}$ away); actually, a part of the geographical catchment areas of Reggio Calabria and Lamezia Terme airports are overlapping and similar in terms of population and income trends.

The application refers to the period January-June 2009 (i.e. current situation); the air passenger demand and the number of movements at the airport in this period have been, respectively, 245,943 and 3,669 (official source: www.assaeroporti.it). The surface mode choice percentages have been computed by direct surveys at the airport during three representative weekly periods; more than $78 \%$ of air travelers use their cars, about $4 \%$ travels by taxi and the remaining by public modes (buses and also ships, as the airport also serves the city of Messina on the other side of the Messina Strait). The airport has its own parking area, but this is small with respect to the user requests and many travelers park outside the landside, in the neighborhood of the airport.

The airside configuration is really simple, as the airport has just one runway also serving as taxiway, and an aircraft parking area located near the airport passenger terminal, so passengers move on foot from the terminal to the aircraft, given the very short distances. Handling vehicles too move on very short distances, given the airside size. Aircraft using the airport are A319-A320, B733 and MD80. 
A survey about the actual airport carbon footprint has been made with reference to the average day in the considered period, by using suitable devices to collect data about the carbon concentration in different points of the landside and around (but very near to) the airport area.

Following the several steps described in the previous sections, the different carbon impact contributions have been estimated, as well as the overall contribution that has been compared with the measured one. Aircraft ground-based unit emissions have been obtained by official data, as well as average land vehicle emissions.

Carbon concentration at a given point has been estimated by considering available pollutant dispersion models (e.g. TRRL [33]; Caline 4 [34]). The comparison between estimated and measured concentrations shows a good approximation (about $11 \%$ difference).

As regards the carbon impact contribution, more then $62 \%$ has been due to road vehicles, about $9 \%$ to handling vehicles and the remaining to aircraft-related operations. The overall airport carbon footprint is greatly within the prescriptive range, as the test case refers to a small airport also located in a windy area where pollutants are relatively quickly dispersed. As expected, the application allows the different carbon impact contributions to be estimated, so transport planners and airports can identify the best strategies to promote an airport sustainable development.

The procedure has been applied in a simplified form, by using more statistical, current data than predictive, mathematical models as the first goal was to test the overall performance of the procedure. Obviously, the most appealing use is in term of prediction, by suitably specifying all the involved models briefly described in the previous sections.

\section{SUMMARY AND MAIN CONCLUSIONS}

The procedure presented in this paper proposes a comprehensive framework to assess the airport carbon footprint directly linked to the transport function. Impacts produced at an airport are due to not only aircraft but also handling vehicles and private cars used by travelers going in and out of the airport. The main steps have been identified in order to compute the carbon contribution of the different components and then estimate their share. Such a procedure allows transport planners and airports to compute the carbon contribution due to the different sources and then promote a sustainable airport development by adopting strategies that minimize the larger contributions.

An application to a test case, although in simplified version, has given very promising results thus suggesting the need to adopt a broad point of view when identifying sustainable developing strategies. Apart from the numerical results, that strongly depend on the specific examined situation, the procedure allows the different carbon impact contributions to be estimated separately and also suggested further developments. In fact, many improvements can still be obtained by best exploring the modeling of some steps, as the relationship among handling vehicles, scheduled aircraft and airside configuration as well as the identification of the choice dimension sequence in the demand stage models, mainly for predictive purposes.

\section{REFERENCES}

[1] Upham, P., Thomas, C., Gillingwater, D. \& Raper, D., Environmental capacity and airport operations: current issues and future prospects. Journal of Air Transport Management, 9, pp. 145-151, 2003. doi:10.1016/S0969-6997(02)00078-9

[2] Goetz, A. R. \& Graham, B., Air transport globalization, liberalization and sustainability: post 2001 policy dynamics in the United States and Europe. Journal of Transport Geography, 12, pp. 265-276, 2004. doi:10.1016/j.jtrangeo.2004.08.007

[3] Lenzen, M., Murray, S.A., Kortec, B. \& Dey, C.J., Environmental impact assessment including indirect effects. A case study using input-output analysis. Environmental Impact Assessment Review, 23, pp. 263-282, 2003. doi:10.1016/S0195-9255(02)00104-X 
[4] Graham, B. \& Guyer, C., Environmental sustainability, airport capacity and European air transport liberalization: irreconcilable goals? Journal of Transport Geography, 7, pp. 165-180, 1999. doi:10.1016/S0966-6923(99)00005-8

[5] Graham, A., Managing the Airports: An International Prospective, 2nd edn, Elsevier, 2003.

[6] International Civil Aviation Organization, Environmental Protection, Annex 16 - Vol I, Aircraft Noise, Montreal, 1993.

[7] Directive 2002/49/EC of the European Parliament and the Council of 25 June 2002 relating to the assessment and management of environmental noise.

[8] Air Transport Action Group, www.atag.org.

[9] Yu, K.N., Cheung, Y.P., Cheung T. \& Henry, R.C., Identifying the impact of large urban airports on local air quality by nonparametric regression. Atmospheric Environment, 38, pp. 4501-4507, 2004. doi:10.1016/j.atmosenv.2004.05.034

[10] Schürmann, G., Schäfer K., Jahn, C., Hoffmann, H., Bauerfeind, M., Fleuti, E. \& Rappenglück B., The impact of NOx, CO and VOC emissions on the air quality of Zurich airport. Atmospheric Environment, 41, pp. 103-118, 2007. doi:10.1016/j.atmosenv.2006.07.030

[11] Unal, A., Hu, Y., Chang, M.E., Odman, M.T. \& Russell, A.G., Airport related emissions and impacts on air quality: application to the Atlanta International Airport. Atmospheric Environment, 39, pp. 5787-5798, 2005. doi:10.1016/j.atmosenv.2005.05.051

[12] Lu, C. \& Morrell, P., Determination and applications of environmental costs at different sized airports - aircraft noise and engine emissions. Transportation, 33, pp. 45-61, 2006. doi:10.1007/s11116-005-2300-y

[13] European Commission, Multi-annual indicative TEN-T programme (MAP) for the period 2007-2013, COM(2006)245, 25 May 2006.

[14] American Planning Association, The language of traffic. http://www.planning. org/ thecommissioner/19952003/spring02.htm, 2005, accessed December 6.

[15] Sheffi, Y., Urban Transportation Networks: Equilibrium Analysis with Mathematical Programming Methods, Prentice Hall: Englewood Cliffs, 1985.

[16] Box, G.E.P. \& Jenkins, G.M., Time-series Analysis, Forecasting and Control, Holden-Day: San Francisco, 1970.

[17] Judge, G.G., Griffiths, W.E., Lutkepohl, H., Hill, R.C. \& Lee T.-C., Introduction to the Theory and Practice of Econometrics, 2nd edn, Wiley \& Sons, Inc., 1988.

[18] Karlaftis, M.G. \& Papastavrou, J.D., Demand characteristics for charter air-travel. International Journal of Transport Economics, XXV(3), pp. 19-35, 1998.

[19] Hensher D.A., Determining passenger potential for a regional airline hub at Canberra International Airport. Journal of Air Transport Management, 8, pp. 301-311, 2002. doi:10.1016/S0969-6997(02)00010-8

[20] Lim, C. \& McAleer, M., Time series forecasts of international travel demand for Australia. Tourism Management, 23, pp. 389-396, 2002. doi:10.1016/S0261-5177(01)00098-X

[21] Inglada, V. \& Rey, B., Spanish air travel and September 11 terrorist attacks: a note. Journal of Air Transport Management, 10, pp. 441-443, 2004. doi:10.1016/j.jairtraman.2004.06.002

[22] Postorino, M.N., Air demand modelling: overview and application to a developing regional airport (Chapter 4). Developments of Regional Airports: Theoretical Analyses and Case Studies, ed. M.N. Postorino, WIT Press: UK, 2009.

[23] Train, K., Discrete Choice Methods with Simulation, Cambridge University Press: Cambridge, MA, 2003.

[24] Harvey, G., Airport choice in a multiple airport region. Transportation Research, 21A, pp. 439-449, 1987. 
[25] Innes, J.D. \& Doucet, D.H., Effects of access distance and level of service on airport choice. Journal of Transportation Engineering, 116(4), pp. 507-516, 1990. doi:10.1061/(ASCE)0733947X(1990)116:4(507)

[26] Pels, E., Nijkamp, P. \& Rietveld P., Access to and competition between airports: a case study for the San Francisco Bay Area. Transportation Research, 37A, pp. 71-83, 2003.

[27] Kroes, E., Lierens A. \& Kouwenhoven, M., The airport network and catchment area competition model: a comprehensive airport demand forecasting system using a partially observed database. RAND Europe, Conference reference: ERSA, 2005.

[28] Hess, S. \& Polak, J.W., Mixed logit modelling of airport choice in multi-airport regions. Journal of Air Transport Management, 11, pp. 59-68, 2005.

[29] Suzuki, Y., Modelling and testing the "two-step" decision process of travellers in airport and airline choices. Transportation Research, 43E, pp. 1-20, 2007.

[30] Hess, S., Modelling air travel choice behaviour. Developments of Regional Airports: Theoretical Analyses and Case Studies, ed. M.N. Postorino, WIT Press: UK, 2009. doi:10.1016/j. jairtraman.2004.09.001

[31] Ashford, N. \& Wright, P.H., Airport Engineering, 3rd edn, Wiley \& Sons, Inc., 1992.

[32] Intergovernmental Panel of Climate Change, Fourth Assessment Report, http://www.ipcc.ch/ ipccreports/sres/aviation.

[33] Hickman, A.J. \& Colwill D.M., The estimation of air pollution concentrations from road traffic, TRRL Laboratory, Report 1052, 1982.

[34] Benson P.E., CALINE 4. A dispersion model for predicting pollutant concentrations near roadways, FHHWA/CA/TL 84/15, California Department of Transportation, Sacramento (CA), 1986. 